\title{
Penerapan Data Mining Dalam Pengelompokkan Data Nilai Siswa Untuk Penentuan Jurusan Siswa Pada SMA Tamora Menggunakan Algoritma K-Means Clustering
}

\author{
Yohanni Syahra \\ Program Studi Informasi, STMIK Triguna Dharma
}

\begin{tabular}{l}
\hline \hline Article Info \\
\hline Article history: \\
Received Mei $15^{\text {th }}, 2018$ \\
Revised June $28^{\text {th }}, 2018$ \\
Accepted Aug $06^{\text {th }}, 2018$
\end{tabular}

\section{Keyword:}

Penentuan Jurusan

Clustering

Algoritma K-Means

\begin{abstract}
ABSTRAK
Penjurusan siswa Sekolah Menengah Atas merupakan usaha peningkatan kualitas pendidikan yang langsung berkenaan dengan siswa sebagai salah satu bagian dari peningkatan SDM. Penentuan jurusan yang dilakukan selama ini mempunyai banyak kelemahan, antara lain berdasarkan keinginan siswa tanpa melihat latar belakang nilai akademisnya dan tidak ada acuan yang yang jelas untuk melakukan pengelompokkan data nilai siswa.

Untuk dapat menyelesaikan permasalahan yang ada maka dibuatlah sebuah sistem untuk pengelompokkan nilai siswa untuk penentuan jurusan dengan menerapkan salah satu metode Clustering dan algoritma yang digunakan adalah Algoritma K-Means untuk mengidentifikasi objek yang serupa dengan memperhatikan beberapa kriteria.

Dengan demikian hasil dari pengelompokan yang telah dirancang akan membantu pihak SMA Tamora dalam proses Pengelompokkan nilai Siswa untuk penentuan Jurusan yang sesuai dengan kriteria, sehinga pengelompokan dapat dilakukan lebih cepat, tepat dan akurat serta terhindar dari kesalahan.
\end{abstract}

Copyright @ 2018 STMIK Triguna Dharma. All rights reserved. $\begin{array}{ll}\text { First Author } & \\ \text { Nama } & \text { : Yohanni Syahra, S.Si, M.Kom }\end{array}$

Program Studi : Sistem Informasi STMIK Triguna Dharma

Email

\section{PENDAHULUAN}

Penjurusan siswa Sekolah Menengah Atas merupakan usaha peningkatan kualitas pendidikan yang langsung berkenaan dengan siswa sebagai salah satu bagian dari peningkatan SDM. Sesuai kurikulum yang berlaku di seluruh Indonesia, maka siswa kelas X SMA yang naik ke kelas XI akan mengalami penjurusan.

Penjurusan siswa ini bertujuan untuk mengarahkan peserta didik agar lebih fokus mengembangkan kemampuan diri dan minat yang dimiliki. Jurusan yang tidak tepat bisa sangat merugikan siswa dan karirnya di masa mendatang. Dengan penjurusan tersebut diharapkan dapat memaksimalkan potensi, bakat atau talenta individu, sehingga juga akan memaksimalkan nilai akademisnya. Penentuan jurusan yang dilakukan selama ini mempunyai banyak kelemahan, antara lain berdasarkan keinginan siswa tanpa melihat latar belakang nilai akademisnya dan tidak ada acuan yang yang jelas untuk melakukan pengelompokkan data siswa. Sehingga jurusan yang dipilih terkadang menjadi masalah bagi siswa di kemudian hari.

Data Mining adalah proses yang mempekerjakan satu atau lebih teknik pembelajaran komputer (machine learning) untuk menganalisis dan mengektrasi pengetahuan (knowledge) secara otomatis. Dalam Data Mining terdapat beberapa teknik salah satunya adalah klastering. Klastering digunakan untuk menganalisis pengelompokkan data nilai siswa yang memiliki karakteristik tertentu . Algoritma yang akan diterapkan dari klastering ini adalah K-Means.

\section{LANDASAN TEORITIS}

\subsection{Data Mining}

Menurut Hermawati (2013:3) "Data Mining adalah proses yang mempekerjakan satu atau lebih teknik pembelajaran komputer (machine learning) untuk menganalisis dan mengekstraksi pengetahuan (knowledge) secara otomatis." Data Mining berisi pencarian trend atau pola yang diinginkan dalam database besar untuk membantu pegambilan keputusan di waktu yang akan datang. 


\subsection{Algoritma K-Means}

Algoritma K-Means merupakan metode analisis kelompok yang mengarah pada pemartisian $\mathrm{N}$ objek pengamatan ke dalam kelompok (cluster) dimana setiap objek pengamatan dimiliki oleh sebuah kelompok dengan mean (rata-rata) terdekat,mirip dengan algoritma Expectation-Maximization untuk Gaussian Mixture dimana keduanya mencoba untuk menemukan pusat dari kelompok dalam data sebanyak iterasi perbaikan yang dilakukan oleh kedua algoritma. (Prasetyo, 2012:178)

Berikut ini adalah langkah-langkah algoritma K-Means:

1. Tentukan $\mathrm{K}$ sebagai jumlah cluster yang dibentuk.

2. Tentukan pusat (centroid) cluster awal.

digunakan rumus sebagai berikut

keterangan :

$$
C_{i}=\frac{1}{M} \sum_{j=1}^{M} X_{j}
$$

$C_{i}:$ centroid pada cluster

$x_{j}$ : objek ke-j

M : banyaknya objek/jumlah objek yang menjadi anggota cluster

3. Perhitungan

Untuk mengukur jarak antar data dengan pusat cluster digunakan Euclidian Distance.. Rumusnya adalah

Keterangan :

$$
\mathrm{D}\left(x_{2}, x_{1}\right)=\left\|x_{2}-x_{1}\right\|_{2}=\sqrt{\sum_{j=1}^{p}\left|x_{2}-x_{i j}\right|^{2}}
$$

$$
\begin{array}{ll}
x_{2} & : \text { data } \\
x_{1} & : \text { titik pusat (centroid) } \\
\mathrm{D}\left(x_{2}, x_{1}\right) & : \text { Euclidian Distance yaitu jarak antara data } x_{2} \text { dan } x_{1}
\end{array}
$$

4. Pengelompokkan data

setelah sejumlah populasi data tersebut menemukan kedekatan dengan salah satu centroid yang ada maka secara otomatis populasi data tersebut masuk kedalam kelas yang memiliki centroid yang bersangkutan.

5. Lakukan iterasi, kemudian tentukan posisi centroid baru dengan menggunakan persamaan [2.1]

6. Ulangi langkah 3 apabila masih ada data yang berpindah kelompok, atau ada perubahan nilai centroid diatas nilai ambang yang ditentukan, atau juga apabila perubahan nilai pada fungsi objektif yang digunakan masih diatas nilai ambang yang ditentukan.

7. Tentukan $\mathrm{K}$ sebagai jumlah cluster yang dibentuk.

8. Tentukan pusat (centroid) cluster awal.

Dalam menenetukan $\mathrm{n}$ buah pusat cluster awal dilakukan pembangkitan bilangan random yang merepresentasikan urutan data input. Pusat awal cluster didapatkan dari data sendiri bukan dengan menentukan titik baru, yaitu dengan mengacak (random) pusat awal dari data. Kemudian untuk menghitung centroid cluster ke-I berikutnya digunakan rumus sebagai berikut

$$
C_{i}=\frac{1}{M} \sum_{j=1}^{M} X_{j}
$$

keterangan :

$C_{i}:$ centroid pada cluster

$x_{j}$ : objek ke-j

M : banyaknya objek/jumlah objek yang menjadi anggota cluster

9. Perhitungan

Untuk mengukur jarak antar data dengan pusat cluster digunakan Euclidian Distance. Jarak hasil perhitungan akan dilakukan perbandingan dan dipilih jarak terdekat antar data dengan pusat cluster, jarak ini mengunakan bahwa data tersebut berada dalam satu kelompok dengan pusat cluster terdekat. Rumusnya adalah :

$$
\mathrm{D}\left(x_{2}, x_{1}\right)=\left\|x_{2}-x_{1}\right\|_{2}=\sqrt{\sum_{j=1}^{p}\left|x_{2}-x_{i j}\right|^{2}}
$$

Keterangan :

$$
\begin{array}{ll}
x_{2} & : \text { data } \\
x_{1} & : \text { titik pusat (centroid) } \\
\mathrm{D}\left(x_{2}, x_{1}\right) & : \text { Euclidian Distance yaitu jarak antara data } x_{2} \text { dan } x_{1}
\end{array}
$$


10. Pengelompokkan data

setelah sejumlah populasi data tersebut menemukan kedekatan dengan salah satu centroid yang ada maka secara otomatis populasi data tersebut masuk kedalam kelas yang memiliki centroid yang bersangkutan.

11. Lakukan iterasi, kemudian tentukan posisi centroid baru dengan menggunakan persamaan [2.1]

12. Ulangi langkah 3 apabila masih ada data yang berpindah kelompok, atau ada perubahan nilai centroid diatas nilai ambang yang ditentukan, atau juga apabila perubahan nilai pada fungsi objektif yang digunakan masih diatas nilai ambang yang ditentukan.

\section{ANALISIS DAN HASIL}

Analisa permasalahan bertujuan untuk mengetahui dan mengamati permasalah yang sedang terjadi, kemudian merumuskan sebuah solusi untuk menyelesaikan permasalahan yang ada. Untuk jurusan yang sesuai dengan minat, maka diperlukan informasi dan pengetahuan tentang informasi nilai rata-rata bidang studi siswa.

\section{Tabel 1 Data Siswa}

\begin{tabular}{|c|c|c|c|c|}
\hline No & Nama Siswa & Nilai Rata-Rata IPA & Nilai Rata-Rata IPS & Nilai Tes Ujian Umum \\
\hline 1 & Abimana Syahputra & 80 & 80 & 88 \\
\hline 2 & Agung Ramadhan & 75 & 75 & 70 \\
\hline 3 & Agustina Dwi Ningsih & 81 & 88 & 91 \\
\hline 4 & Aisya Aulya & 85 & 80 & 85 \\
\hline 5 & Akhir Ramadhan & 72 & 78 & 86 \\
\hline 6 & Alysa Syaftia & 80 & 88 & 77 \\
\hline 7 & Amalini Hilwa Hadijah & 81 & 91 & 92 \\
\hline 8 & Amelia Putri Hartawan & 90 & 87 & 91 \\
\hline 9 & Ananda Tiara & 79 & 81 & 80 \\
\hline 10 & Andi Syahputra Siregar & 78 & 92 & 80 \\
\hline 11 & Andri Hariono & 91 & 80 & 95 \\
\hline 12 & Arida Afika Putri & 80 & 88 & 89 \\
\hline 13 & Asrul Adam & 70 & 78 & 85 \\
\hline 14 & Ayu Mitri & 92 & 93 & 90 \\
\hline 15 & Bella Syahfitri & 92 & 82 & 93 \\
\hline 16 & Benny Situmorang & 77 & 88 & 80 \\
\hline 17 & BoyChandra S & 80 & 78 & 80 \\
\hline 18 & Chandra Hutagalung & 76 & 70 & 91 \\
\hline 19 & Cici Lestari & 85 & 73 & 78 \\
\hline 20 & Citra Kirana & 93 & 80 & 91 \\
\hline 21 & Dedek Ridzki Wiranata & 81 & 82 & 80 \\
\hline 22 & Deni Yuswanto & 78 & 87 & 80 \\
\hline 23 & Desi Kesuma Wardani & 86 & 90 & 87 \\
\hline 24 & Desi Purnama & 91 & 88 & 93 \\
\hline 25 & Deva Mahendra & 75 & 77 & 80 \\
\hline 26 & Devi Paramitha & 73 & 70 & 80 \\
\hline 27 & Dewi Suheni & 93 & 78 & 85 \\
\hline 28 & Dewi Utami & 86 & 86 & 82 \\
\hline 29 & Dian Murni Dewi & 76 & 78 & 80 \\
\hline 30 & Dimas Anggara & 93 & 80 & 85 \\
\hline 31 & Dimas Candi Gatot & 78 & 78 & 80 \\
\hline 32 & Dimas Prasetyo & 77 & 78 & 80 \\
\hline 33 & Erik Manalakson & 91 & 70 & 85 \\
\hline 34 & Erina Ghasani & 88 & 84 & 80 \\
\hline
\end{tabular}




\begin{tabular}{|l|l|c|c|c|}
35 & Erma Wati & 85 & 78 & 80 \\
\hline 35 & Erma Wati & 85 & 78 & 80 \\
\hline 36 & Ervan Mahardika & 92 & 80 & 90 \\
\hline 37 & Esna Surya Putra & 78 & 80 & 80 \\
\hline 38 & Faisal Tri Hanafi & 80 & 78 & 90 \\
\hline 39 & Fitri Handayani & 92 & 86 & 87 \\
\hline 40 & Hakim Fahrezi & 94 & 86 & 85 \\
\hline.. & & & & \\
\hline.. & & & & 93 \\
\hline.. & & & 78 & 80 \\
\hline 127 & Trisia Wulandari & 80 & 84 & \\
\hline 128 & Ulfa Miftahul & 78 & & \\
\hline
\end{tabular}

Berikut langkah-langkah clustering menggunakan algoritma k-means.

1. Tentukan jumlah cluster yang diinginkan (misalk=4)

2. Pilih centroid awal secara acak: pada langkah ini secara acak akan dipilih 4 buah data sebagai centroid, misalnya: data $\{40,20,14,10)$

M1 $=(94,86,85)$, M2=(93,80,91), M3=(92,93,90),M4=(78,92,80)

3. Hitung jarak dengan centroid .......(iterasi 1)

Pada langkah ini setiap data akan ditentukan centroid terdekatnya, dan data tersebut akan ditetapkan sebagai anggota kelompok yang terdekat dengan centroid.

Untuk menghitung jarak ke centroid masing-masing cluster pada siswa sbb:

Data: $(1,3)$, centroid M1:(94,86,85), M2 $=(93,80,91), \mathrm{M} 3=(92,93,90), \mathrm{M} 4=(78,92,80)$

$\mathrm{DM} 1=\sqrt{(80-94)^{2}+\left(80-86^{2}+(88-85)^{2}\right.}=15,52$

$\mathrm{DM} 2=\sqrt{\left(80-93^{2}+(80-80)^{2}+(88-91)^{2}\right.}=26,59$

$\mathrm{DM} 3=\sqrt{\left(80-92^{2}+(80-93)^{2}+(88-90)^{2}\right.}=14,46$

DM4 $=\sqrt{(80-78)^{2}+(80-92)^{2}+(88-80)^{2}}=10,82$

Tabel hasil perhitungan jarak selengkapnya antara masing-masing data dengan centroid :

Tabel 2 Hasil Perhitungan Iterasi 1

\begin{tabular}{|c|l|c|c|c|c|c|c|}
\hline No & \multicolumn{1}{|c|}{ Nama Siswa } & $\begin{array}{c}\text { Pusat } \\
\mathbf{m 1}\end{array}$ & $\begin{array}{c}\text { Pusat } \\
\mathbf{m} 2\end{array}$ & $\begin{array}{c}\text { Pusat } \\
\mathbf{m 3}\end{array}$ & $\begin{array}{c}\text { Pusat } \\
\mathbf{m 4}\end{array}$ & $\begin{array}{c}\text { Jarak } \\
\text { Terdekat }\end{array}$ & Klaster \\
\hline 1 & Abimana Syahputra & 15.52 & 13.34 & 17.80 & 14.56 & 13.34 & 2 \\
\hline 2 & Agung Ramadhan & 26.59 & 28.11 & 31.83 & 19.95 & 19.95 & 4 \\
\hline 3 & Agustina Dwi Ningsih & 14.46 & 14.42 & 12.12 & 12.08 & 12.08 & 4 \\
\hline 4 & Aisya Aulya & 10.82 & 10.00 & 15.59 & 14.76 & 10.00 & 2 \\
\hline 5 & Akhir Ramadhan & 23.43 & 21.68 & 25.32 & 16.37 & 16.37 & 4 \\
\hline 6 & Alysa Syaftia & 16.25 & 20.71 & 18.38 & 5.39 & 5.39 & 4 \\
\hline 7 & Amalini HilwaHadijah & 15.59 & 16.31 & 11.36 & 12.41 & 11.36 & 3 \\
\hline 8 & Amelia Putri & 7.28 & 7.62 & 6.40 & 17.03 & 6.40 & 3 \\
\hline 9 & Ananda Tiara & 16.58 & 17.83 & 20.32 & 11.05 & 11.05 & 4 \\
\hline 10 & Andi Syahputra & 17.80 & 22.14 & 17.23 & 0.00 & 0.00 & 4 \\
\hline 11 & Andri Hariono & 12.04 & 4.47 & 13.96 & 23.19 & 4.47 & 2 \\
\hline 12 & Arida Afika Putri & 14.70 & 15.39 & 13.04 & 10.05 & 10.05 & 4 \\
\hline 13 & Asrul Adam & 25.30 & 23.85 & 27.09 & 16.88 & 16.88 & 4 \\
\hline 14 & Ayu Mitri & 8.83 & 13.08 & 0.00 & 17.23 & 0.00 & 3 \\
\hline 15 & Bella Syahfitri & 9.17 & 3.00 & 11.40 & 21.56 & 3.00 & 2 \\
\hline 16 & Benny Situmorang & 17.83 & 21.00 & 18.71 & 4.12 & 4.12 & 4 \\
\hline 17 & Boy Chandra S & 16.88 & 17.15 & 21.66 & 14.14 & 14.14 & 4 \\
\hline 18 & Chandra Hutagalung & 24.82 & 19.72 & 28.04 & 24.68 & 19.72 & 2 \\
\hline 19 & Cici Lestari & 17.29 & 16.79 & 24.35 & 20.35 & 16.79 & 2 \\
\hline
\end{tabular}




\begin{tabular}{|l|l|c|c|c|c|c|c|}
\hline 20 & Citra Kirana & 8.54 & 0.00 & 13.08 & 22.14 & 0.00 & 2 \\
\hline 21 & Dedek Ridzki & 14.49 & 16.40 & 18.49 & 10.44 & 10.44 & 4 \\
\hline 22 & Deni Yuswanto & 16.79 & 19.87 & 18.22 & 5.00 & 5.00 & 4 \\
\hline 23 & Desi Kesuma & 9.17 & 12.85 & 7.35 & 10.82 & 7.35 & 3 \\
\hline 24 & Desi Purnama & 8.77 & 8.49 & 5.92 & 18.81 & 5.92 & 3 \\
\hline 25 & Deva Mahendra & 21.61 & 21.31 & 25.40 & 15.30 & 15.30 & 4 \\
\hline 26 & Devi Paramitha & 26.87 & 24.92 & 31.46 & 22.56 & 22.56 & 4 \\
\hline 27 & Dewi Suheni & 8.06 & 6.32 & 15.84 & 21.12 & 6.32 & 2 \\
\hline 28 & Dewi Utami & 8.54 & 12.88 & 12.21 & 10.20 & 8.54 & 1 \\
\hline 29 & Dian Murni Dewi & 20.32 & 20.35 & 24.10 & 14.14 & 14.14 & 4 \\
\hline 30 & Dimas Anggara & 6.08 & 6.00 & 13.96 & 19.85 & 6.00 & 2 \\
\hline 31 & Dimas Candi Gatot & 18.57 & 18.71 & 22.83 & 14.00 & 14.00 & 4 \\
\hline 32 & Dimas Prasetyo & 19.44 & 19.52 & 23.45 & 14.04 & 14.04 & 4 \\
\hline 33 & Erik Manalakson & 16.28 & 11.83 & 23.56 & 26.04 & 11.83 & 2 \\
\hline 34 & Erina Ghasani & 8.06 & 12.73 & 14.04 & 12.81 & 8.06 & 1 \\
\hline 35 & Erma Wati & 13.04 & 13.75 & 19.34 & 15.65 & 13.04 & 1 \\
\hline 36 & Ervan Mahardika & 8.06 & 1.41 & 13.00 & 20.98 & 1.41 & 2 \\
\hline
\end{tabular}

Pada langkah ini dihitung pula rasio antara besaran BCV (Between Cluster Variation) dengan WCV(Within Cluster Variation) :

$$
\begin{aligned}
& \mathrm{d}(\mathrm{m} 1 . \mathrm{m} 2)=\sqrt{(94-93)^{2}+(86-80)^{2}+(85-91)^{2}}=8,54 \\
& \mathrm{~d}(\mathrm{~m} 1 . \mathrm{m} 3)=\sqrt{(94-92)^{2}+(86-93)^{2}+(85-90)^{2}}=8,83 \\
& \mathrm{~d}\left(\mathrm{~m} 1 . \mathrm{m} 4=\sqrt{(94-78)^{2}+(86-92)^{2}+(85-80)^{2}}=17,80\right. \\
& \mathrm{d}(\mathrm{m} 2 . \mathrm{m} 3)=\sqrt{(93-92)^{2}+(80-93)^{2}+(91-90)^{2}}=13,08 \\
& \mathrm{~d}(\mathrm{~m} 2 . \mathrm{m} 4)=\sqrt{(93-78)^{2}+(80-92)^{2}+(91-80)^{2}}=22,14 \\
& \mathrm{~d}(\mathrm{~m} 3 . \mathrm{m} 4)=\sqrt{(92-78)^{2}+(93-92)^{2}+(90-80)^{2}}=17,23 \\
& B C V=\mathrm{d}(\mathrm{m} 1 . \mathrm{m} 2)+\mathrm{d}(\mathrm{m} 1 . \mathrm{m} 3)+\mathrm{d}(\mathrm{m} 1 . \mathrm{m} 4)+\mathrm{d}(\mathrm{m} 2 \cdot \mathrm{m} 3)=\mathrm{d}(\mathrm{m} 2 . \mathrm{m} 4)+\mathrm{d}(\mathrm{m} 3 . \mathrm{m} 4) \\
& =8,54+8,83+17,80+13,08+22,14+17,23 \\
& =87,63
\end{aligned}
$$

Hitung nilai WCV (Within Cluster Variation) dengan cara memangkatkan jarak terdekat cluster dan menjumlahkan setiap nilai $W C V$.

$$
\begin{aligned}
& W C V=13,34^{2}+19,95^{2}+12,08^{2} \ldots .+8,00^{2} \\
& W C V=14908
\end{aligned}
$$

Sehingga besar rasio $=B C V / W C V=87,63 / 14908=0.005$

Karena langkah ini merupakan iterasi 1 maka lanjutkan kelangkah berikutnya. Pusat cluster baru ditentukan berdasarkan pengelompokkan anggota dari masing-masing cluster.

Ulangi iterasi yang dimulai dari langkah 1, sampai rasio tetap atau cluster tidak mengalami perubahan.

Disini sampai dengan iterasi 4 , karena bila dibandingkan maka rasio sekarang $(0,014)$ sudah tidak lagi lebih besar dari rasio sebelumnya $(0,014)$ oleh karena itu iterasi dihentikan.

Dari hasil klastering diatas dapat diambil kesimpulan bahwa :

1. kelompok siswa pada klaster 1 merupakan kelompok siswa yang masuk ke jurusan IPA 1 dengan jumlah 33 siswa.

2. Kelompok siswa pada klaster 2 merupakan kelompok siswa yang masuk ke jurusan IPA 2 dengan jumlah 16 siswa.

3. Kelompok siswa pada klaster 3 merupakan kelompok siswa yang masuk ke jurusan IPS 1 dengan jumlah 33 siswa.

4. Kelompok siswa pada klaster 4 merupakan kelompok siswa yang masuk ke jurusan IPS 2 dengan jumlah 46 siswa.

\section{KESIMPULAN}

Berdasarkan hasil dari perancangan aplikasi penerapan data mining dalam pengelompokkan data nilai siswa untuk penentuan jurusan menggunakan algoritma K-Means, maka dapat diperoleh beberapa kesimpulan. Adapun kesimpulan tersebut adalah sebagai berikut : 
1. Data mining dengan algoritma K-Means dapat diterapkan pada SMA Tamora untuk menganalisis permasalahan yang ada yang berkenaan dengan pengelompokkan data nilai siswa untuk penentuan jurusan.

2. Aplikasi dirancang dengan mengadopsi algoritma $K$-Means yang dapat digunakan dalam pengelompokkan data nilai siswa untuk pennetuan jurusan pada SMA Tamora.

3. Aplikasi yang dirancang dapat mengimplementasikan dan dapat dijadikan sebagai solusi pemecahan masalah dalam hal pengelompokkan data nilai siswa untuk penentuan jurusan siswa pada SMA Tamora.

\section{DAFTAR PUSTAKA}

A.M. Hirin. 2012. VB.Net 2010. ANDI : Yogyakarta

Hermawati, FA, 2013. Data Mining. ANDI : Yogyakarta.

Nofriansyah, D, 2015. Algoritma Data Mining Dan Pengujiannya. Deepublish

Ong Jhon Oscar. 2013. Implementasi Algoritma K-Means Clustering Untuk Menentukan Strategi Marketing President University. Bekasi : Jurnal

Prasetyo, Eko, 2012. Konsep Dasar Data Mining Menggunakan Matlab. ANDI : Yogyakarta

Rosa A.S \& M.Shalahudin. 2013. Rekayasa Perangkat Lunak.Informatika : Bandung.

Sulindawaty dan Fathoni, M, 2010. Pengantar Analisa Perancangan Sistem. (Jurnal SAINTIKOM Vol. 9, No 2) hal $14-17$

Tohari, Hamim, 2014. Analisis Serta Perancangan Sistem Informasi Melalui Pendekatan UML. ANDI : Yogyakarta

\section{BIOGRAFI PENULIS}

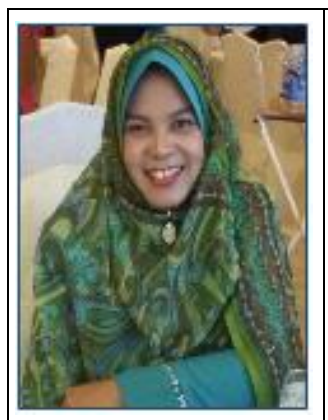

Yohanni Syahra, S. Si., M. Kom, Perempuan kelahiran Medan, 29 Oktober 1982 saat ini beliau menduduki jabatan Sekretaris Program Studi Sistem Informasi STMIK Triguna Dharma, tamat Universitas Sumatera Utara Bidang Ilmu Kimia, tamat Universitas Putra Indonesia (UPI-YPTK) Konsentrasi Teknologi Komputer, beberapa mata kuliah diampu, diantaranya : Data Mining Dan Data Warehouse, Sistem Pakar, Komputer Multimedia, Komputer Akuntansi, Sistem Basis Data, Aplikasi Finansial, Paket Program Niaga. 